\title{
Impact of Impeller Stagger Angles on Pressure Fluctuation for a Double-Suction Centrifugal Pump
}

\author{
Da-Chun Fu' ${ }^{1}$ Fu-Jun Wang ${ }^{1,2}$, Pei-Jian Zhou ${ }^{3}$, Ruo-Fu Xiao ${ }^{1,2}$ and Zhi-Feng Yao ${ }^{1,2^{*}}$ (D)
}

\begin{abstract}
Pressure fluctuation may cause high amplitude of vibration of double-suction centrifugal pumps, but the impact of impeller stagger angles is still not well understood. In this paper, pressure fluctuation experiments are carried out for five impeller configurations with different stagger angles by using the same test rig system. Results show that the stagger angles exert negligible effects on the characteristics of head and efficiency. The distributions of pressure fluctuations are relatively uniform along the suction chamber wall, and the maximum pressure fluctuation amplitude is reached near the suction inlet tongue region. The pressure fluctuation characteristics are affected largely by impeller rotation, whose dominant frequencies include impeller rotation frequency and its harmonic frequencies, and half blade passage frequency. The stagger angle exerts a small effect on the pressure fluctuations in the suction chamber while a great effect on the pressure fluctuation in volute casing, especially on the aspect of decreasing the amplitude on blade passage frequency. Among the tested cases, the distribution of pressure fluctuations in the volute becomes more uniform than the other impeller configurations and the level of pressure fluctuation may be reduced by up to $50 \%$ when the impeller stagger angle is close to $24^{\circ}$ or $36^{\circ}$. The impeller structure pattern needs to be taken into consideration during the design period, and the halfway staggered impeller is strongly recommended.
\end{abstract}

Keywords: Double-suction centrifugal pump, Impeller stagger angle, Pressure fluctuation, Frequency spectra analysis

\section{Introduction}

Double-suction centrifugal pumps are widely used in various fields, such as water diversion, farm irrigation, urban water supply, and process industry. The flow rate of a double-suction centrifugal pump is about twice as much as a single-suction centrifugal pump with the same diameter, and the axial force of the former pump is theoretically balanced [1]. In long-distance water diversion projects or high lift irrigations, double-suction centrifugal pumps are playing increasingly important roles, and the scales of which are becoming much larger. For instance, the impeller diameter of a double-suction centrifugal pump in Huinanzhuang pumping station in

\footnotetext{
*Correspondence: yzf@cau.edu.cn

${ }^{1}$ College of Water Resources and Civil Engineering, China Agricultural University, Beijing 100083, China

Full list of author information is available at the end of the article
}

China reaches $1.75 \mathrm{~m}$, and its single installation power is $7500 \mathrm{~kW}[2]$.

The internal flow in a double-suction centrifugal pump is extremely complex, especially under off-design operating conditions [3]. The 3D asymmetric flow pattern in the volute, the fluid dynamics of rotor-stator interaction, the secondary flow, and the cavitation phenomenon induce large pressure fluctuations $[4,5]$. Periodic pressure fluctuation may force the impeller or volute to vibrate, and resonance may occur when the frequency of pressure fluctuation approaches the natural frequency of pump components. The energy of pressure fluctuations propagates in fluids at the speed of sound, which is harmful and unacceptable to the pump and environment. Furthermore, the lowest static pressure during fluctuation may lead to cavitations $[6,7]$. Adverse operating conditions may be detected by observing the pressure fluctuations
SpringerOpen

C The Author(s) 2018. This article is distributed under the terms of the Creative Commons Attribution 4.0 International License (http://creativecommons.org/licenses/by/4.0/), which permits unrestricted use, distribution, and reproduction in any medium, provided you give appropriate credit to the original author(s) and the source, provide a link to the Creative Commons license, and indicate if changes were made. 
generated by a pump, which could provide evidence of inadequate suction conditions [8].

Several studies have characterized the pressure fluctuation of centrifugal pumps through experimental investigations, theoretical analysis, and numerical simulations $[9,10]$. Chu et al. $[11,12]$ tested a single centrifugal pump; built relationships among unsteady flow, pressure fluctuation, and noise; and inspected the interaction effect between the impeller and the volute. This study showed that the impeller-volute tongue interaction and the asymmetric outflow from the impeller are the two main sources of high-level pressure fluctuations. When the gap between the impeller and the volute tongue is less than $20 \%$ of the impeller radius, the amplitude of pressure fluctuation noticeably decreases as the gap increases. Stel et al. [13] has recently presented a numerical investigation of fluid flow in a centrifugal impeller with a vaned diffuser. Significant levels of turbulence and blade-oriented effects are revealed at different flow rates. Pei et al. [14] found the optimization on the impeller of a lowspecific-speed centrifugal pump can even reduce pressure fluctuations. Gao et al. [15] analyzed the unsteady flow inside a large centrifugal pump with stay vanes. The main frequency of pressure fluctuation is the blade passing frequency. The radial gap between the impeller outlet and the volute tongue influences the overall performance and the pressure fluctuations inside the pumps [16, 17]. Hayashi et al. [18] analyzed the pressure fluctuations in a piping system excited by a centrifugal turbomachinery by considering the damping characteristics.

Alqutub et al. [19] investigated the effect of the V cut of the impeller outlet on pressure fluctuation in doublesuction centrifugal impellers and found that the $\mathrm{V}$ cut decreases pressure fluctuation. Spence et al. [20] numerically simulated a double-suction centrifugal pump with impeller staggered at $0^{\circ}, 15^{\circ}$, and $30^{\circ}$, and found that the stagger impeller largely affects the characteristics of pressure fluctuation. For such impeller configurations, looking from the pump outlet section toward the twin impellers, the blades of both impellers can be aligned along the exit width or staggered. Yang et al. [21] and Li et al. [22] implemented numerical simulations for staggered impellers and illustrated that a suitable stagger angle may reduce the amplitude of pressure fluctuations. Yao et al. [23] reported that a double-suction impeller with staggered bilateral blades can reduce pressure fluctuations in comparison with the traditional impeller. Staggered impellers have already been used in Huinanzhuang pumping station, but the effect of stagger angle on the pressure fluctuation remains unclear because of the rare experimental investigations on this issue.

In the present study, pressure fluctuation experiments are carried out for five impeller arrangements with the same test rig system to establish the relationship between impeller stagger angles and pressure fluctuations for a double-suction centrifugal pump. High-accuracy pressure transducers are mounted along the walls of the semi-casing suction chamber and the volute casing. Fluctuating pressure signals are captured and recorded under different operation conditions. Time domains of the pressure signals are analyzed using statistical methods and Fast Fourier Transform (FFT). The influence of impeller stagger angles on pressure fluctuations is obtained successfully.

\section{Tested Pump and Experimental Setup}

The tested pump (300ss-37) is manufactured by Shandong Shuanglun Co., Ltd. (S.S.G.). The inlet and outlet diameters of the pump are 300 and $250 \mathrm{~mm}$, respectively. The trailing edge of the original double-suction impeller blade is parallel with the pump rotation shaft, and the blades on both sides are arranged in a non-staggered layout. The specific speed $N_{\mathrm{s}}$ of the impeller is 185 , which is defined as $N_{s}=(3.65 n \sqrt{Q / 2}) / H^{3 / 4}$. Different from those of the traditional double-suction impeller, the hubs of the tested impellers extend to the impeller outlet. The main design parameters of the test pump are given in Table 1. The design flow rate is $1030 \mathrm{~m}^{3} / \mathrm{h}$, the design head is $37 \mathrm{~m}$, and the design efficiency is $85 \%$. The design rotational speed is $1480 \mathrm{r} / \mathrm{min}$.

Both sides of the impeller are manufactured separately to stager the double-suction impeller. Some specific key slots are set on the pump shaft in the peripheral direction. In this way, one side of the impeller can be connected with keyways at a specific stagger angle with the other side. According to the different impeller stagger angles listed in Table 2, five impeller configurations are shown in Figure 1 . The stagger angles are $0^{\circ}, 12^{\circ}, 24^{\circ}, 36^{\circ}$, and $48^{\circ}$, which correspond to impellers $1,2,3,4$, and 5 . The absolute values of the stagger angles of impellers 2 and 5 , as well as impellers 3 and 4, are exactly the same,

\section{Table 1 Design parameters of tested pump}

\begin{tabular}{ll}
\hline Main geometric data & Value \\
\hline Impeller inlet diameter $D_{1} / \mathrm{mm}$ & 250.6 \\
Impeller outlet diameter $D_{2} / \mathrm{mm}$ & 367 \\
Impeller outlet width $b / \mathrm{mm}$ & 35 \\
Blades number $Z$ & 6 \\
Nominal flow rate $Q_{\mathrm{n}} /\left(\mathrm{m}^{3} / \mathrm{h}\right)$ & 1030 \\
Nominal head $H_{\mathrm{n}} / \mathrm{m}$ & 37 \\
Nominal efficiency $\eta_{\mathrm{n}} / \%$ & 85 \\
Nominal rotational speed $n_{\mathrm{n}} /(\mathrm{r} / \mathrm{min})$ & 1480 \\
Specific speed $N_{\mathrm{s}}$ & 185 \\
\hline
\end{tabular}


Table 2 Different impeller stagger angles

\begin{tabular}{llllll}
\hline Impeller number & $\mathbf{1}$ & $\mathbf{2}$ & $\mathbf{3}$ & $\mathbf{4}$ & $\mathbf{5}$ \\
\hline Stagger angle $/\left(^{\circ}\right)$ & 0 & 12 & 24 & 36 & 48 \\
\hline
\end{tabular}
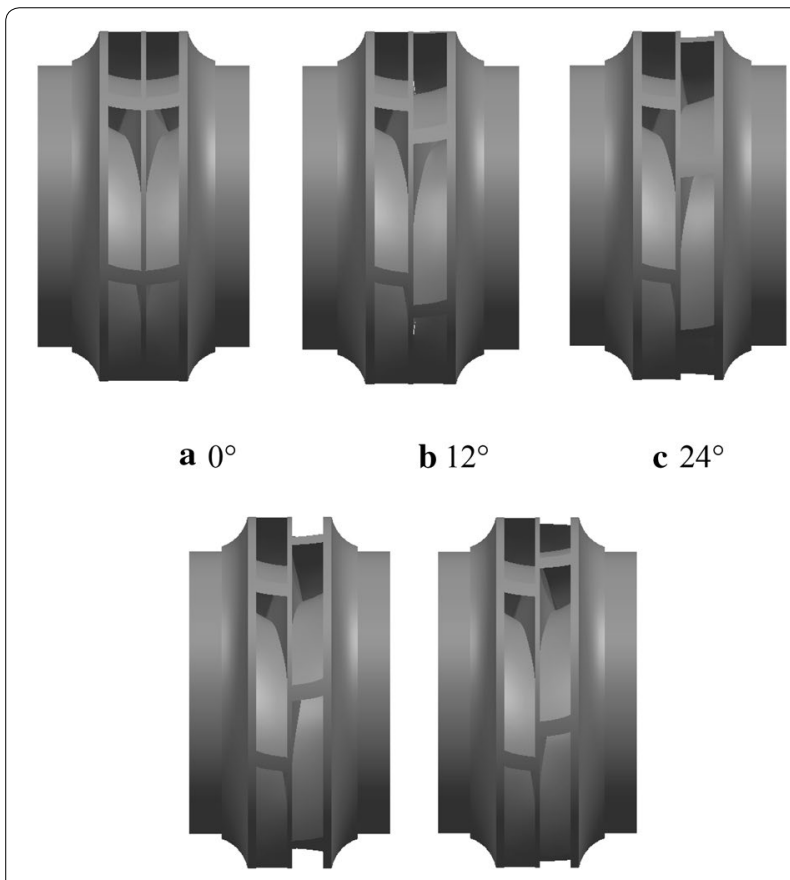

b $12^{\circ}$

c $24^{\circ}$

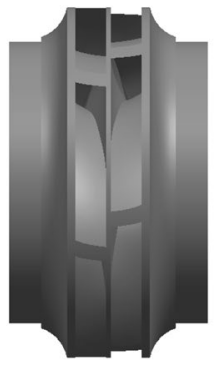

e $48^{\circ}$
Figure 1 Five impeller configurations with impeller stagger angles $0^{\circ}, 12^{\circ}, 24^{\circ}, 36^{\circ}$ and $48^{\circ}$

but the two sides of the blades are staggered in opposite directions.

The experiment is carried out on the open test rig at Shandong Shuanglun Co., Ltd. (S.S.G.). The investigated pump is installed in the test rig containing all necessary components to control the operating point of the pump. The tested pump is driven by an electric AC-motor. The shaft torque and rotating speed are measured by a torque and speed sensor, respectively. Static pressure values at the inlet and outlet of the pump are measured by a pressure differential transfer. The flow rate is determined by a magnetic flow meter. The total uncertainty of the efficiency is around $\pm 0.5 \%$. A scheme of the test rig is shown in Figure 2.

For the pressure fluctuation measurement, Druck PTX14000-15 piezoresistive high-frequency pressure transducers are flush mounted in the wall of the semispiral suction chamber and volute casing, the uncertainty of which is $\pm 0.25 \%$.

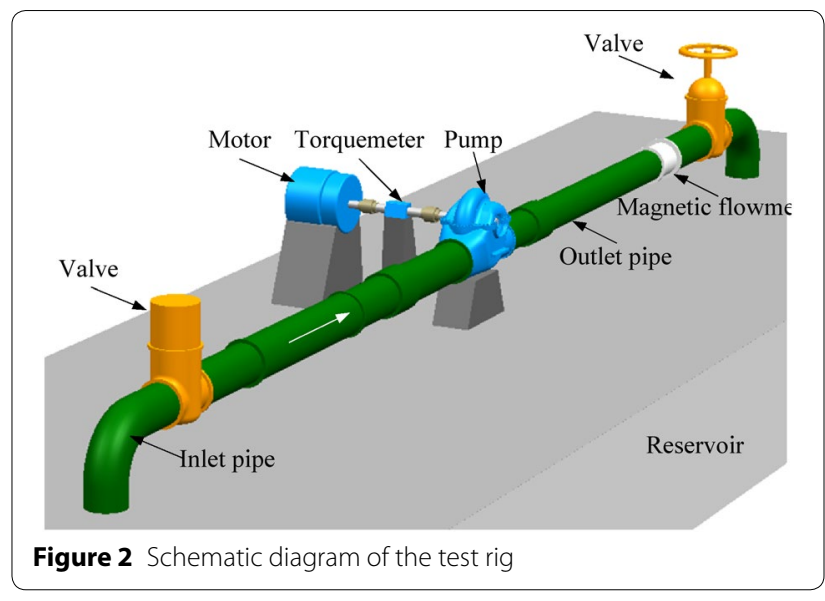

\section{Arrangement of Pressure Measurement Locations}

The investigation mainly focuses on the effects of pressure fluctuations on the semi-spiral suction chamber and the volute casing caused by hydraulic excitations. In the semi-spiral suction chamber, three measurement points are proposed as shown in Figure 3(a). Location $\mathrm{S}_{3}$ is the nearest to the inlet tongue of the suction chamber among the three measurement locations. In the volute casing, measurement points at five circumferential locations in the volute casing wall are presented in Figure 3(b) to obtain the specific frequencies of the pressure fluctuations caused by the interaction between the impeller and the volute tongue.

\section{Test Procedure and Data Acquisition}

The tested operating conditions are adjusted by the valve located in the outlet pipe. Eleven operating conditions are tested within the flow rate range of $0-1.2 Q_{\mathrm{n}}$. Pressure fluctuation transducers output $4-20 \mathrm{~mA}$ signals over their operating range. The signals run across a highaccuracy resistor to generate voltages that are recorded synchronously with the sampling frequency of $2 \mathrm{kHz}$ and sampling time of $30 \mathrm{~s}$ by the acquisition unit. A low-pass filter with a cut frequency of $500 \mathrm{~Hz}$ is set.
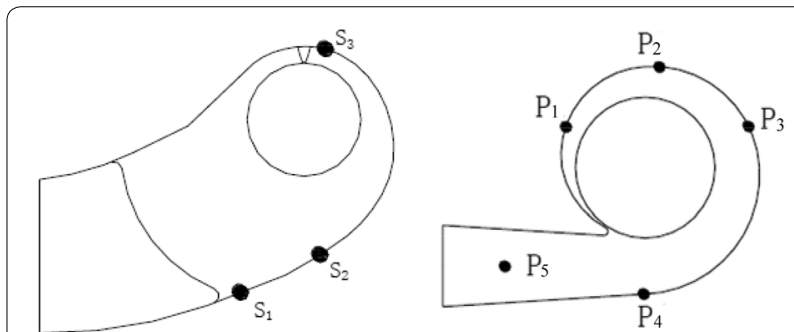

a locations in semi-suction chamber b locations in volute Figure 3 Measurement locations of pressure transducers 
The peak-to-peak value in the time domain with 95\% confidence is adopted to evaluate the level of pressure fluctuations. The FFT method is applied to obtain frequency spectra, and the Hanning window is used to realize the transform.

\section{Results and Discussion}

\subsection{Performance Tests}

During the energy performance tests, the pump is kept at a constant rotational speed. The flow rate is changed by adjusting the valve on the outlet pipe. The flow rate-head curves for the five tested impeller configures are shown in Figure 4. The flow rate-efficiency curves for five tested impeller configures are shown in Figure 5. Results show that the head only slightly decreases when the doublesuction impeller is staggered. A comparison of the performances at best efficiency points for the five impeller configurations is shown in Table 3. The impeller stagger angles may exert negligible effects on the pumping head and efficiency.

\subsection{Pressure Fluctuations in the Semi-spiral Suction Chamber}

Frequency analysis of pressure fluctuations at different flow rates in the semi-spiral suction chamber is carried out. For each location, frequency analysis between 0 and $400 \mathrm{~Hz}$ is presented with results because of the absence of obvious frequencies higher than $400 \mathrm{~Hz}$. For comparison with other scholars' results $[5,10,20,22]$, the pressure fluctuations are normalized to the pressure coefficient $C_{\mathrm{p}}$ defined as $C_{\mathrm{p}}=\left(p_{\mathrm{i}}-\bar{p}_{\mathrm{i}}\right) /\left(0.5 \rho u_{2}^{2}\right)$. Where $\bar{p}_{\mathrm{i}}$ is the average value of the static pressure fluctuation during $10 \mathrm{~s}, p_{\mathrm{i}}$ is the transient static pressure value, $\rho$ is the fluid density, and $u_{2}$ is the impeller outlet circumferential velocity.

Figure 6 shows the time domains of the pressure fluctuations on the best efficiency point at measurement points

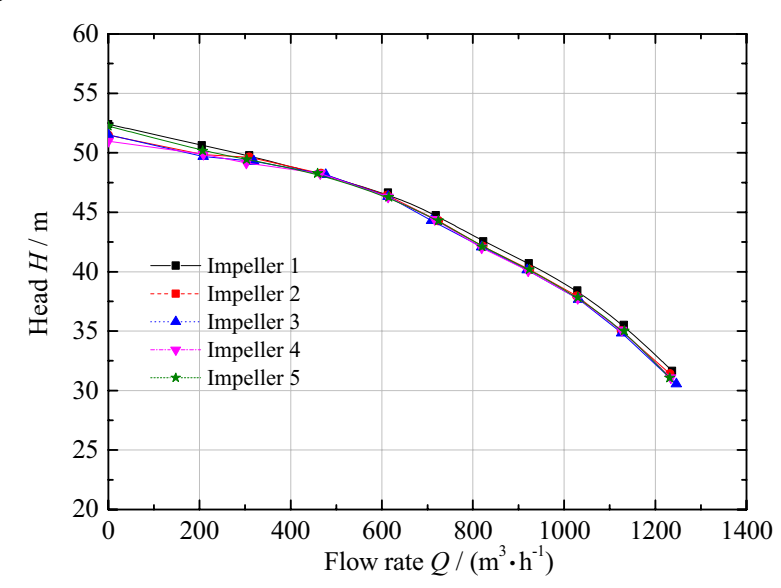

Figure 4 Flow rate-head curves

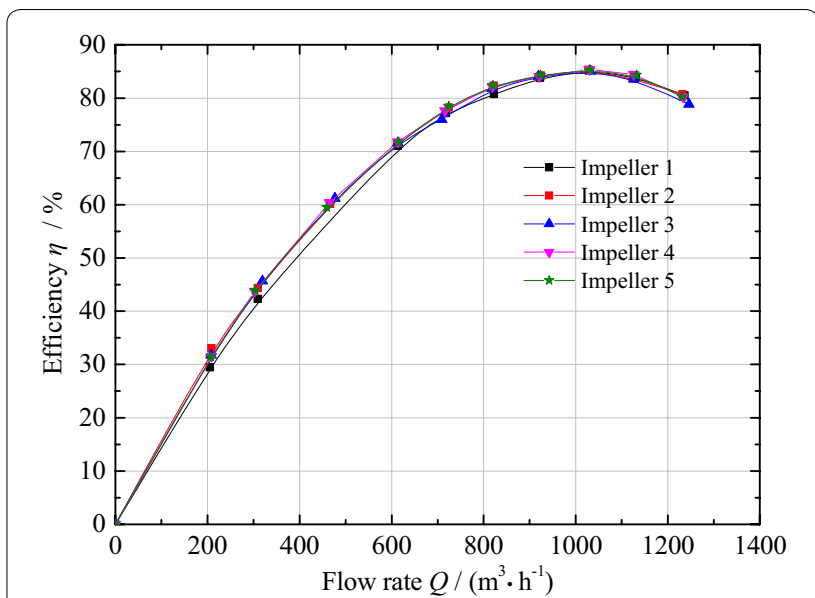

Figure 5 Flow rate-efficiency curves

Table 3 The best efficiency points for five impellers

\begin{tabular}{lrrrrr}
\hline Impeller number & \multicolumn{1}{l}{$\mathbf{l}$} & \multicolumn{1}{l}{$\mathbf{3}$} & \multicolumn{1}{l}{$\mathbf{4}$} & \multicolumn{1}{c}{$\mathbf{5}$} \\
\hline Flow rate $Q /\left(\mathrm{m}^{3} / \mathrm{h}\right)$ & 1028.81 & 1028.20 & 1031.87 & 1029.60 & 1030.08 \\
Head $H / \mathrm{m}$ & 38.89 & 37.93 & 37.67 & 37.78 & 37.84 \\
Efficiency $\eta / \%$ & 85.24 & 85.28 & 85.02 & 85.37 & 85.31 \\
\hline
\end{tabular}

$S_{1}, S_{2}$, and $S_{3}$ on the wall of the semi-suction chamber. Ten periods of impeller rotation are compared for the five impellers, and periodical pressure fluctuations are observed. Among the three measurement points, the highest level of pressure fluctuation appears on the measurement point $S_{3}$, which is located nearest to the inlet tongue. The pressure fluctuation level is the lowest on point $S_{1}$. Such results may be explained by the different distances between the suction chamber and the impeller suction eye. Smaller distance may lead to larger pressure fluctuation. Figure 7 shows the change in the peak-topeak values of pressure fluctuations with the flow rate on the three measurement points for the five impellers. The trends of the peak-to-peak values changing with the flow rate reach a basic agreement on measurement points $S_{1}$, $S_{2}$, and $S_{3}$. During the flow rate range of $0.6-1.0 Q_{n}$ the peak-to-peak values versus flow rate curves are almost the same. The impeller stagger angle exerts negligible effects on the flow field in the suction chamber.

The spectral domains of pressure fluctuations on measurement points $S_{1}, S_{2}$, and $S_{3}$ are shown in Figure 8, which are all operating under nominal conditions. As shown in Figure 8, the blade passage frequency $(148 \mathrm{~Hz})$, half blade passage frequency $(74 \mathrm{~Hz})$, and four times impeller rotation frequency $(98 \mathrm{~Hz})$ are clearly identified in the frequency domains. For measurement point $S_{1}$, the largest amplitude of the pressure fluctuation appears at frequency $98 \mathrm{~Hz}$ for impeller 5, which may be caused by 


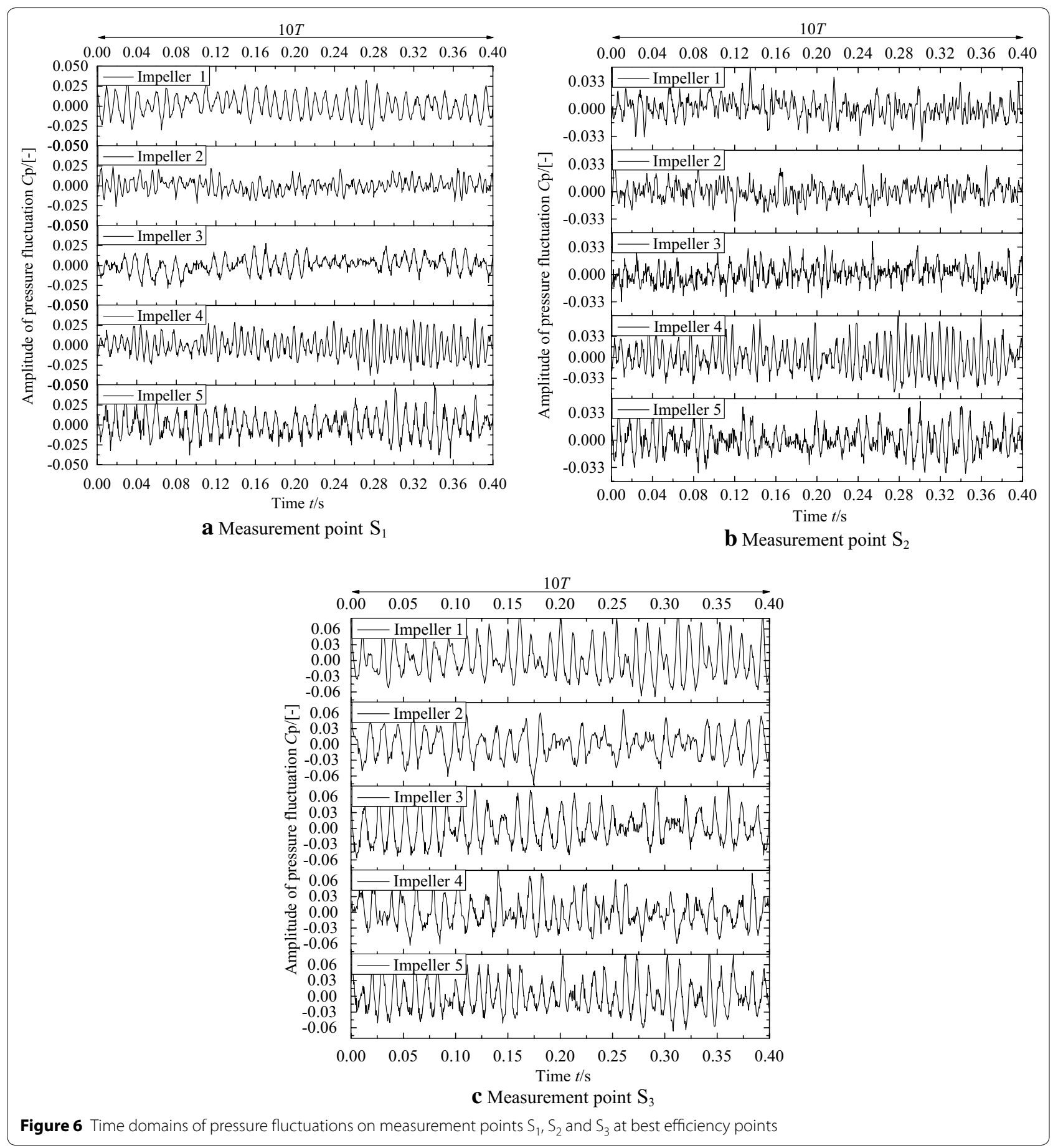

the mechanical source rather than the hydraulic reason. The pressure fluctuation characteristics on point $S_{2}$ are similar to that on point $S_{1}$. The blade passage frequency component on point $S_{2}$ is much more notable than the one on point $S_{1}$, which may reflect the effect of the interaction between the impeller and the inlet tongue in the suction chamber. For the pressure fluctuations on point
$\mathrm{S}_{3}$, the amplitudes at half blade passage frequency and four times impeller rotation frequency are much larger than that on points $S_{1}$ and $S_{2}$.

Figure 9 shows the spectra of the pressure fluctuations at location $S_{3}$ for impeller 1. The amplitudes of pressure fluctuations on half blade passage frequency at 0.2 and $1.2 Q_{\mathrm{n}}$ are 3.9 and 1.6 times of that at the best efficiency 


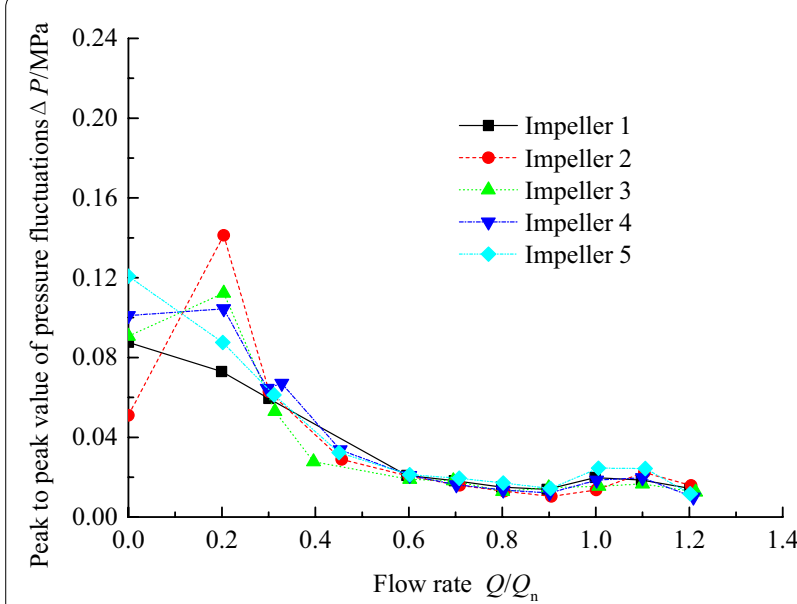

a Measurement point $S_{1}$

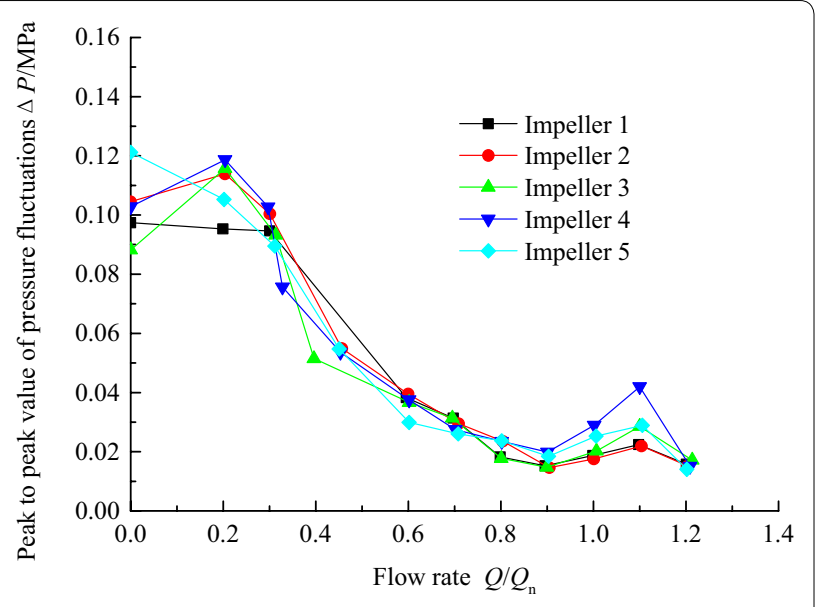

b Measurement point $S_{2}$

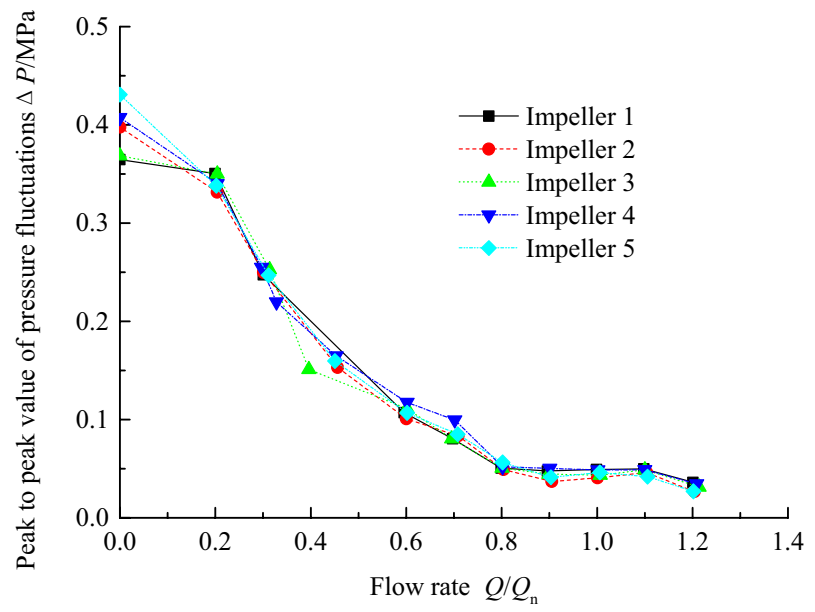

c Measurement point $\mathrm{S}_{3}$

Figure 7 Comparison of peak to peak values for five impellers

point, respectively. In addition, notable white noise phenomenon is present for the pressure signals under 0.2 and $0.6 Q_{n}$ operating conditions. As mentioned by Liu [9], the white noise phenomenon may cause the complex turbulence flow inside the suction region of the test pump.

The pressure fluctuations on half blade passage frequency in Figure 9 show that the amplitude of the pressure fluctuation on such frequency at $1.2 Q_{\mathrm{n}}$ is two times as large as that at $1.0 Q_{n}$. According to the pressure fluctuations reflected by the three measurement points, the characteristics of pressure fluctuations in the suction chamber present a homogeneous distribution. The maximum amplitude of the pressure fluctuations is reached at location $S_{3}$, which is nearest to the suction chamber inlet tongue. The pressure fluctuations in the suction chamber are considerably affected by the rotation effect, of which the frequencies are manifested as the harmonic of impeller rotation frequency and half blade passage frequency.

\subsection{Pressure Fluctuations in the Volute Casing}

In the volute casing, a pronounced pressure fluctuation pattern can be caused by the interaction between the impeller blades and the volute tongue [24, 25]. Figure 10 illustrates the time domains and their corresponding spectral domains at the best efficiency point on measurement point $\mathrm{P}_{1}$. Compared with the frequencies of pressure fluctuations in the suction chamber, the frequencies of pressure fluctuations in the volute are much higher and complicated. The periodicity of the pressure fluctuation in the time domain is not obvious because of the superposition of several frequency components. According to the shown spectra, the main frequencies in the volute are the impeller rotation frequency and its harmonic (25 


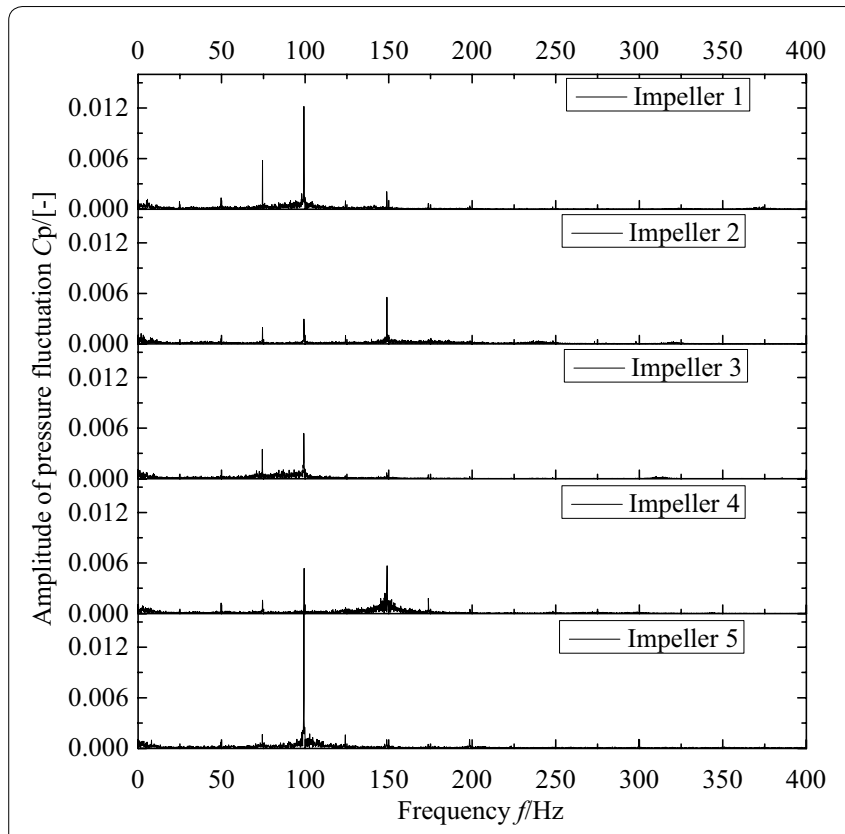

a Measurement point $S_{1}$

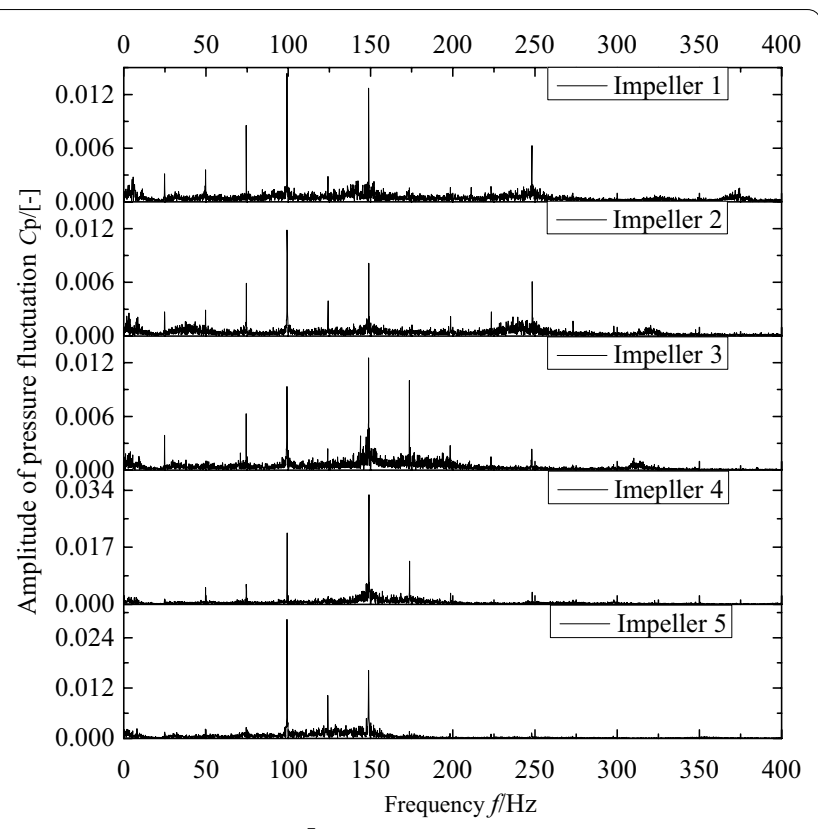

b Measurement point $\mathrm{S}_{2}$

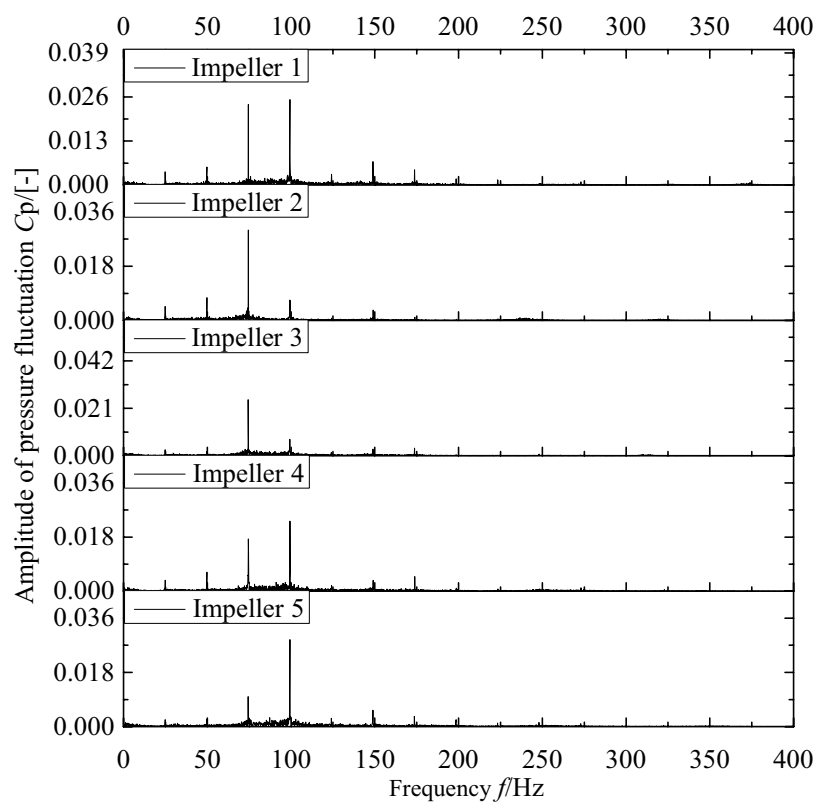

c Measurement point $S_{3}$

Figure 8 Frequency domains of pressure fluctuations on measurement point $S_{1}, S_{2}$ and $S_{3}$ at best efficiency points

and $100 \mathrm{~Hz})$, the half blade passage frequency $(74 \mathrm{~Hz})$, the blade passage frequency and its harmonics (148 and $296 \mathrm{~Hz}$ ), and the broadband frequency [15].

Comparing with that at location $\mathrm{P}_{1}$, the periodicity of the pressure fluctuations at location $\mathrm{P}_{2}$ is much more obvious. The dominant frequency of pressure fluctuation, which is the blade passage frequency, is much more remarkable than that in impellers 1, 2, and 5 (Figure 11). The amplitudes of the pressure fluctuations at the blade passage frequency at location $\mathrm{P}_{2}$ for impellers 3 and 4 are very small [26], and the broadband frequency is observed near the half blade passage frequency.

Figure 12 shows the time and frequency domains of measurement point $\mathrm{P}_{3}$ at the best efficiency points for 


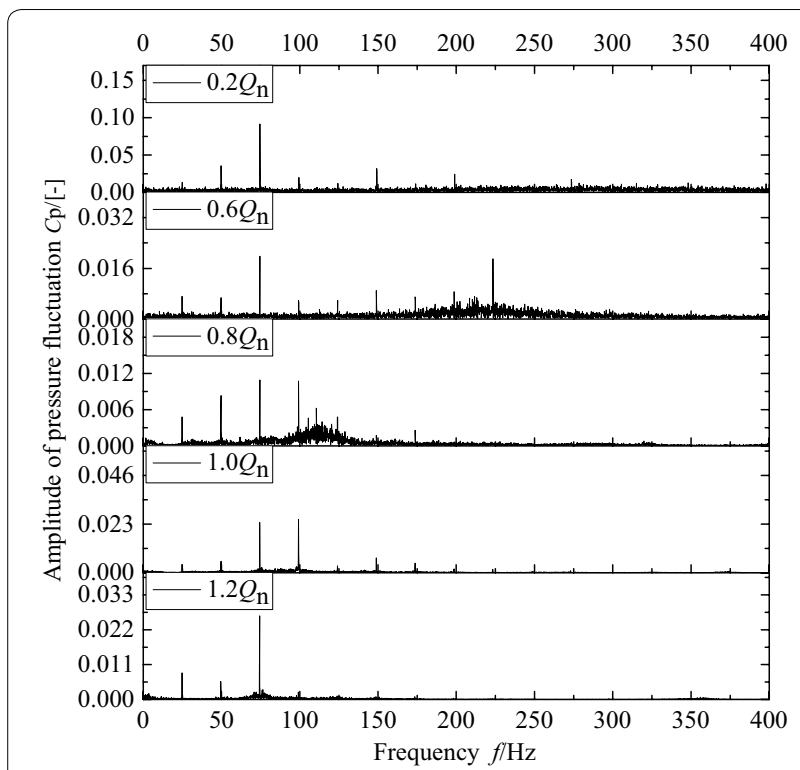

Figure 9 Comparison of spectra of the pressure fluctuations on location $\mathrm{S}_{3}$ for impeller 1

the five impellers. Measurement point $\mathrm{P}_{3}$ is far from the volute tongue, and the level of pressure fluctuation at the blade passage frequency is lower. The harmonic frequencies of the blade passage frequency dominate the pressure fluctuation.

Figure 13 presents the time and frequency domains of measurement point $\mathrm{P}_{4}$ at the best efficiency points for the five impellers. The broadband components greatly affect the pressure fluctuation behaviors at this location. The time and frequency domains of measurement point $\mathrm{P}_{5}$ at the best efficiency points for the five impellers are given in Figure 14. The measurement location is set in the outer volute section, and the characteristics of the pressure fluctuations at this location are basically the same as that at location $\mathrm{P}_{4}$.

Figure 15 shows the peak-to-peak values of the pressure fluctuations as a function of flow rate for the five impellers. In consideration of the above results, the stagger angle greatly affects the pressure fluctuations at location $\mathrm{P}_{2}$. The pressure fluctuation of the staggered impeller is decreased. In addition, the peak-to-peak values of impellers 3 and 4 reduce to $50 \%$ compared with that of impeller 1 . Impellers 3 and 4 have the lowest level of pressure fluctuations, and their impeller stagger angle is $24^{\circ}$ or $36^{\circ}$, which is close to $360 /(2 \cdot \mathrm{Z})$. The stagger angle mainly affects the component of the blade passage frequency but exerts negligible effects on the other components.

Figure 16 present the peak-to-peak values of pressure fluctuations on the volute at different flow rates for impellers 1 and 4 . For impeller 1, the peak-to-peak values at locations $\mathrm{P}_{1}$ and $\mathrm{P}_{2}$, which are close to the volute tongue, are relatively large. The peak-to-peak value is small at locations $\mathrm{P}_{4}$ and $\mathrm{P}_{5}$ set in the diffuse section of the volute, and the smallest one is found at location $\mathrm{P}_{3}$, which is far from the volute tongue. For impeller 4 , the change trends of the peak-to-peak values with flow rate
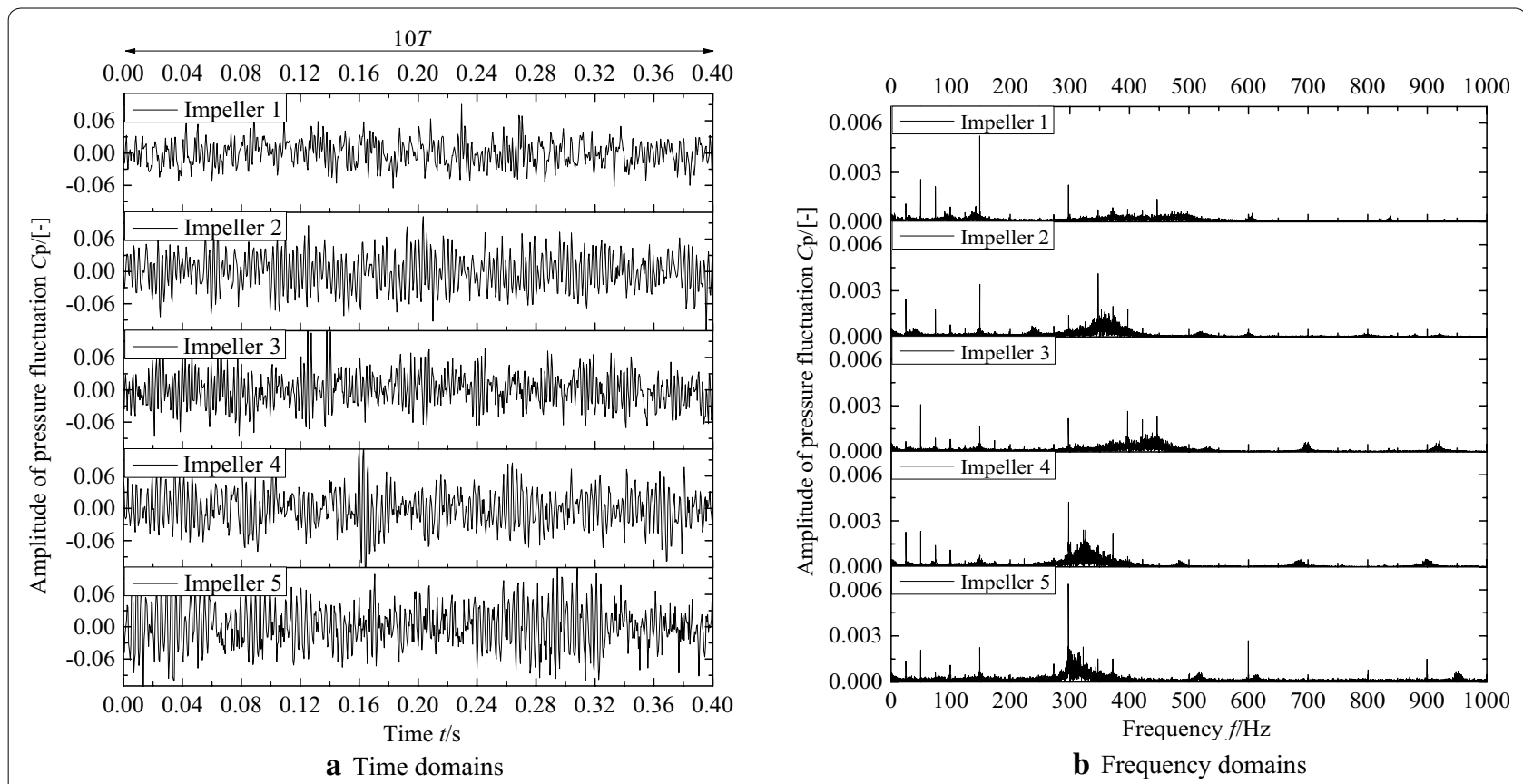

Figure 10 Time and frequency domains of pressure fluctuations on measurement point $P_{1}$ at best efficiency points 

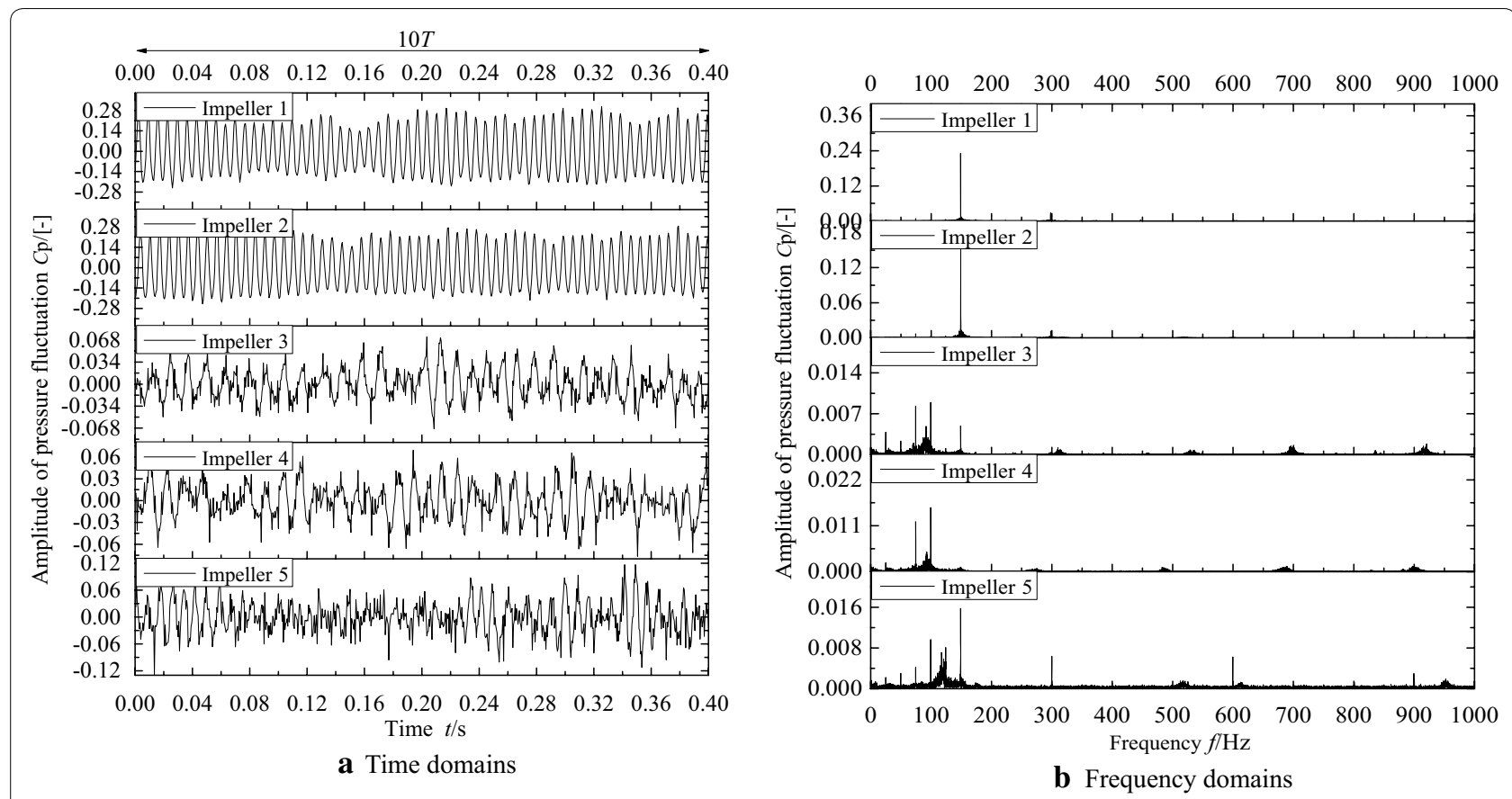

Figure 11 Time and frequency domains of pressure fluctuations on measurement point $\mathrm{P}_{2}$ at best efficiency points

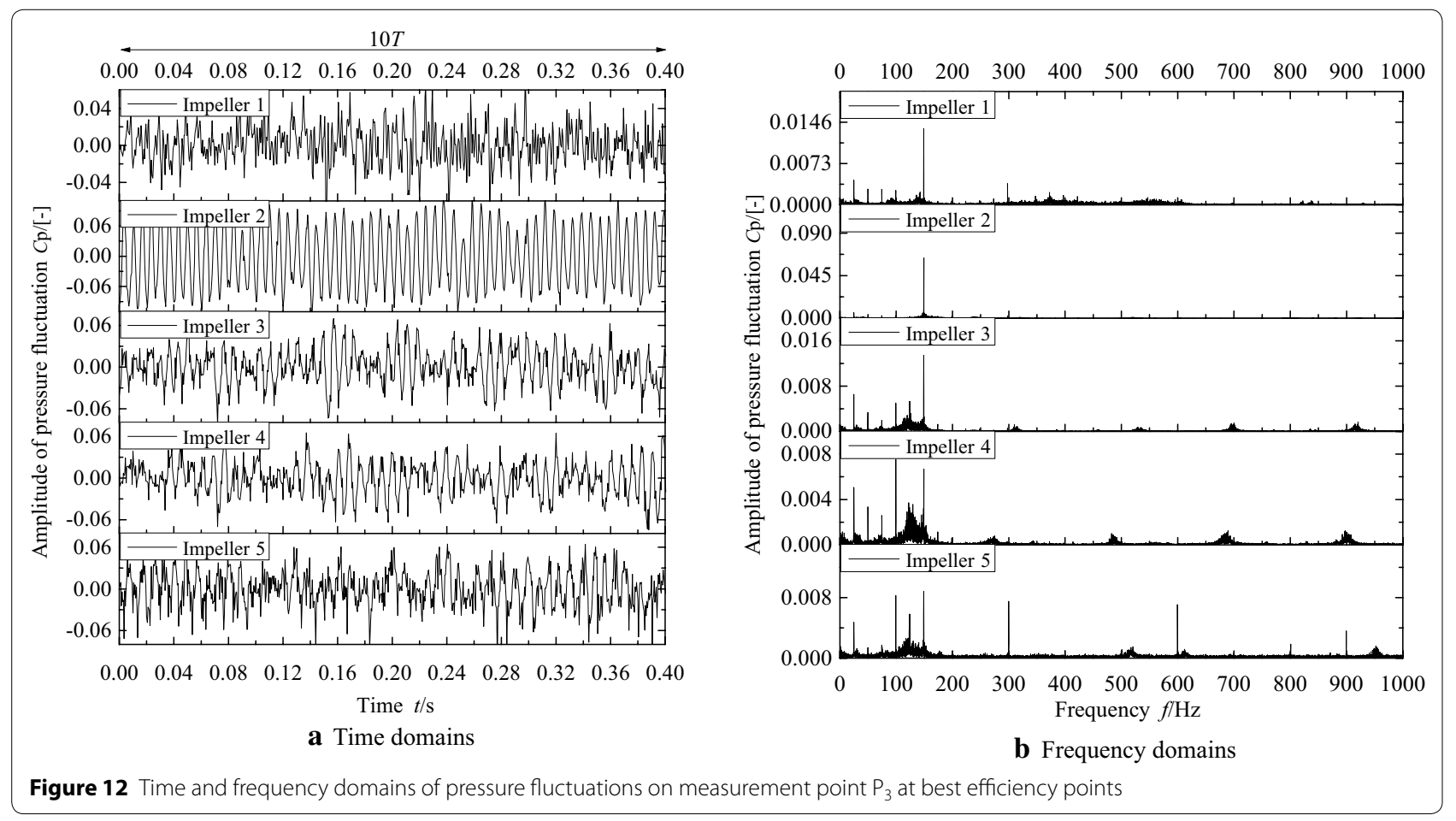

are even, and the discrepancies of the different locations' trends become small. This result is also supported by a previous computational fluid dynamics study [27].
Figure 17 shows the spectra of pressure fluctuations at location $\mathrm{P}_{2}$ for impellers 1 and 4 under the five operating conditions. As observed in the spectra of impeller 1 , 

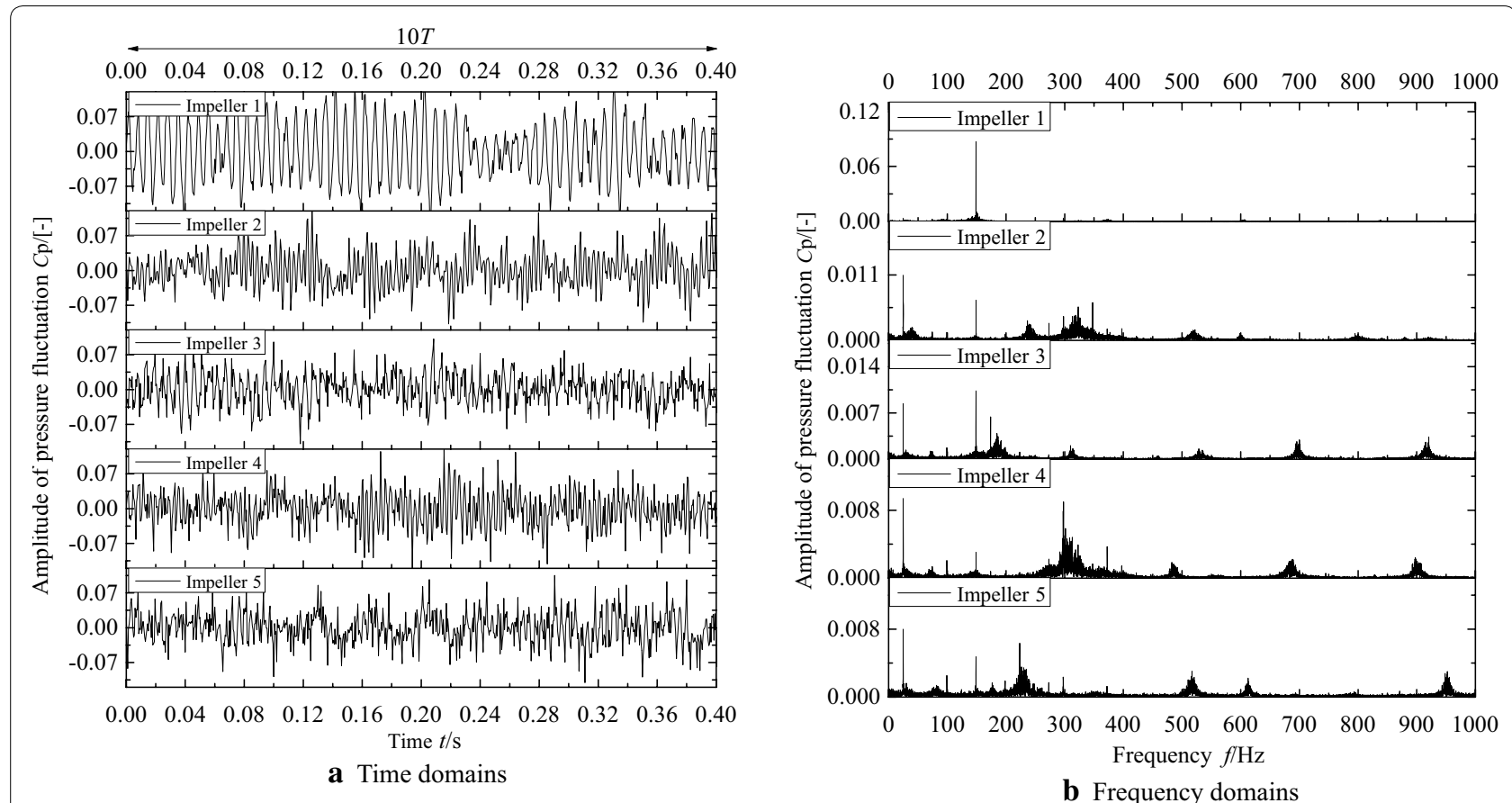

Figure 13 Time and frequency domains of pressure fluctuations on measurement point $\mathrm{P}_{4}$ at best efficiency points

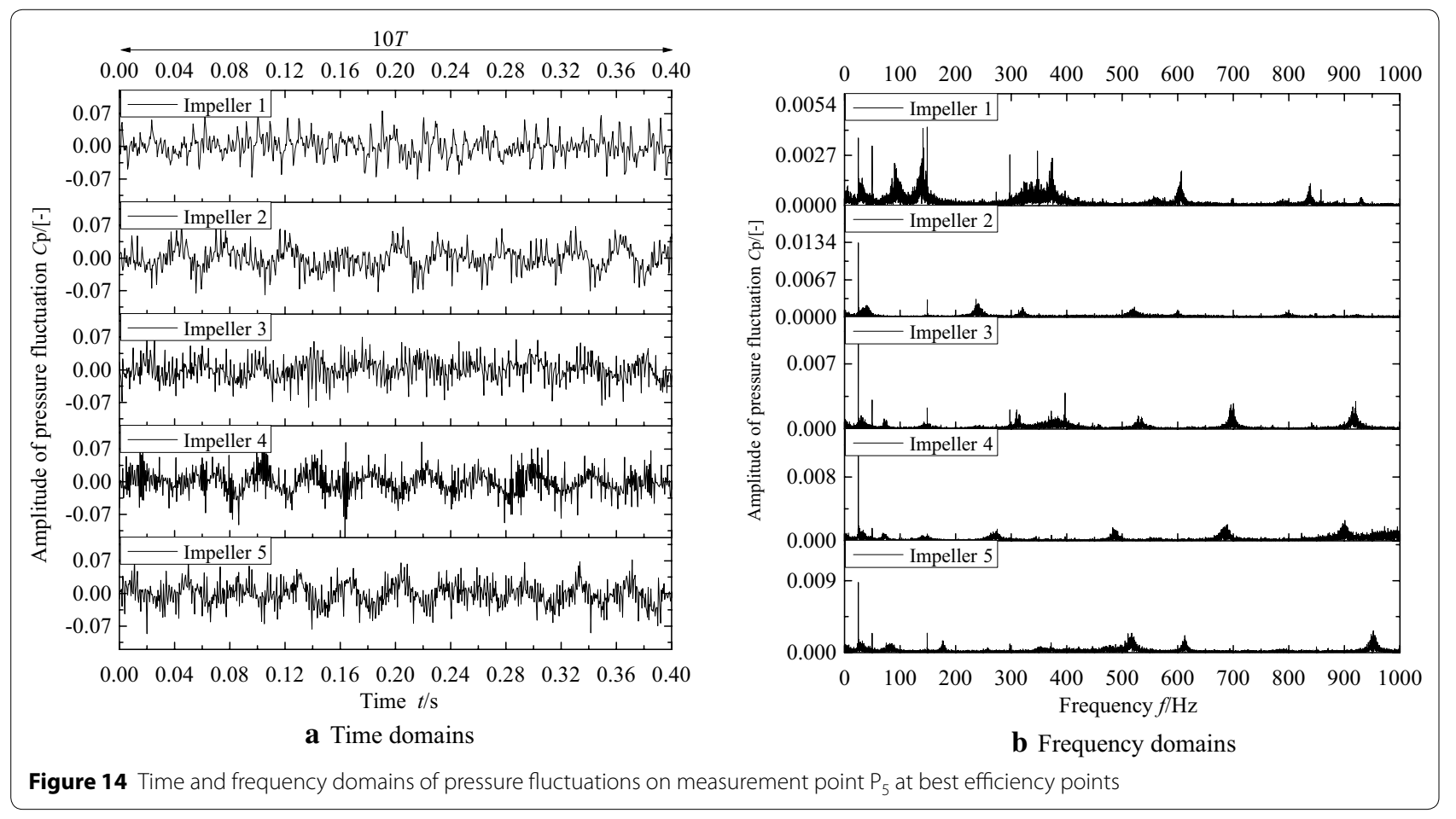

the dominant frequency is always the blade passage frequency, and the broadband component displays remarkably only at $1.2 Q_{n}$, thereby increasing the peak-to-peak value of the pressure fluctuations. For impeller 4, the blade passage frequency only exists at flow rates below $0.6 Q_{n}$. The corresponding amplitude at $0.2 Q_{n}$ is one 


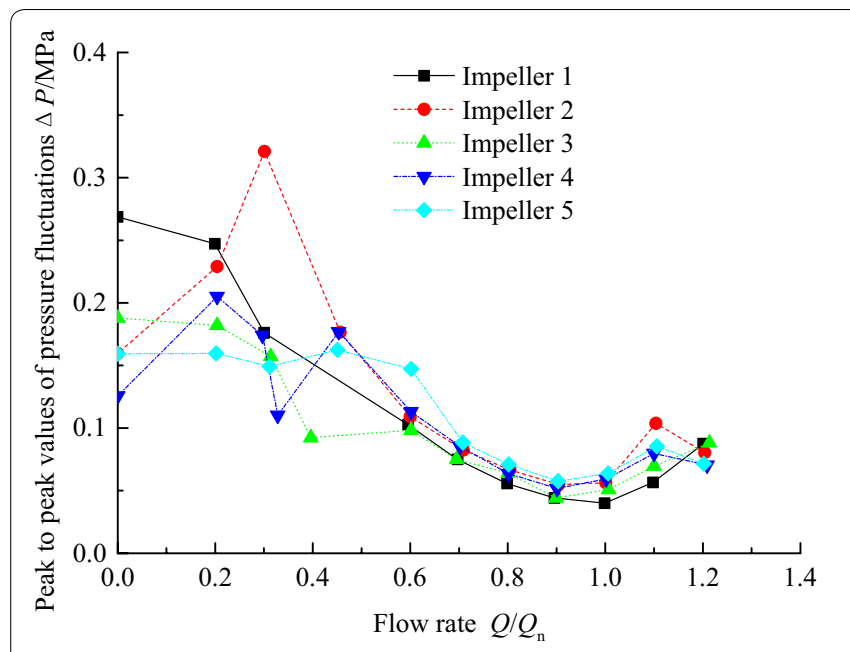

a Measurement point $\mathrm{P}_{1}$

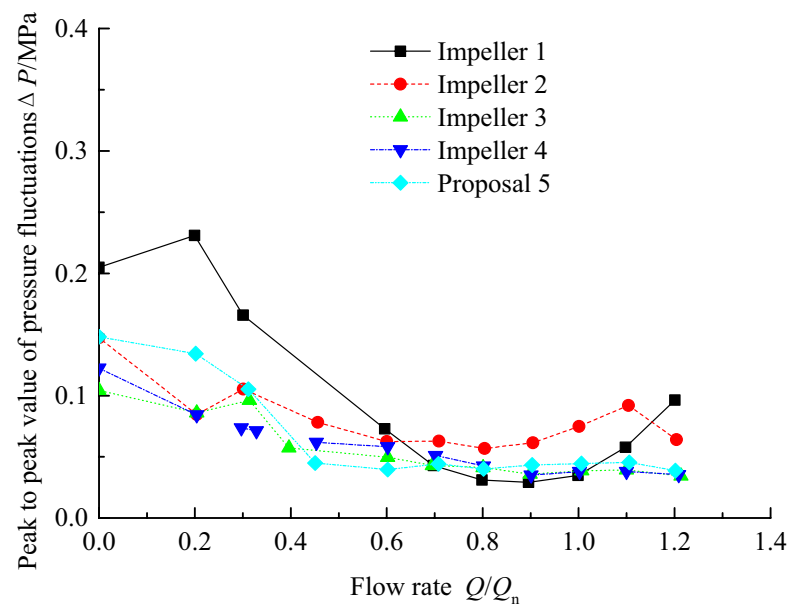

c Measurement point $\mathrm{P}_{3}$

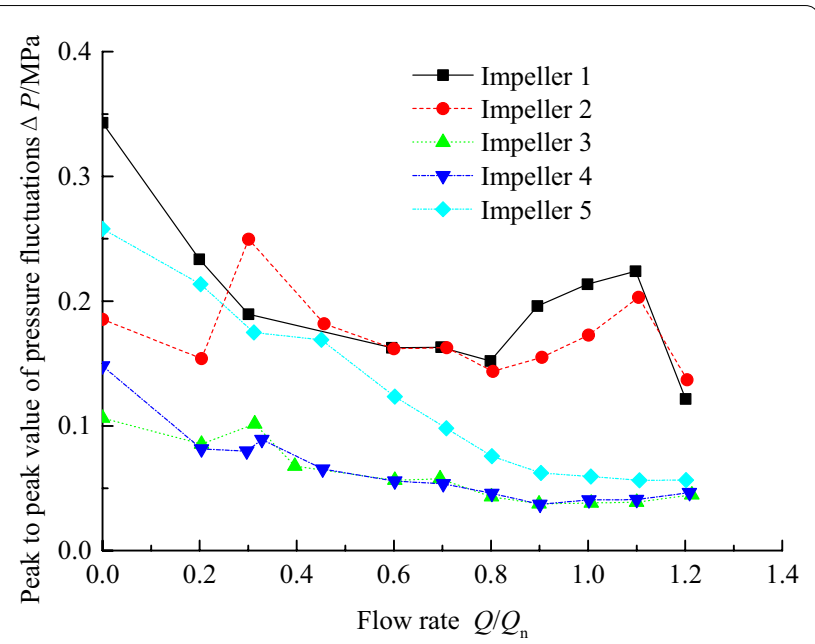

b Measurement point $\mathrm{P}_{2}$

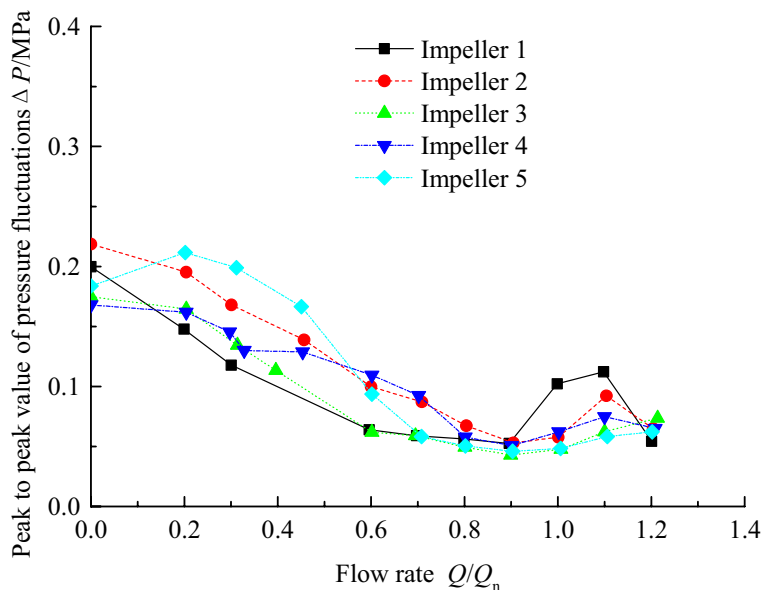

d Measurement point $\mathrm{P}_{4}$

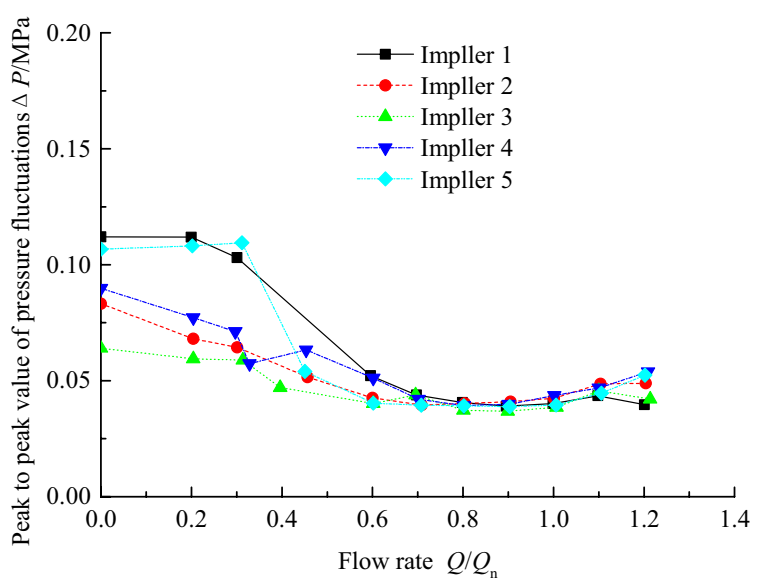

e Measurement point $\mathrm{P}_{5}$

Figure 15 Comparison of peak to peak values for five impellers 


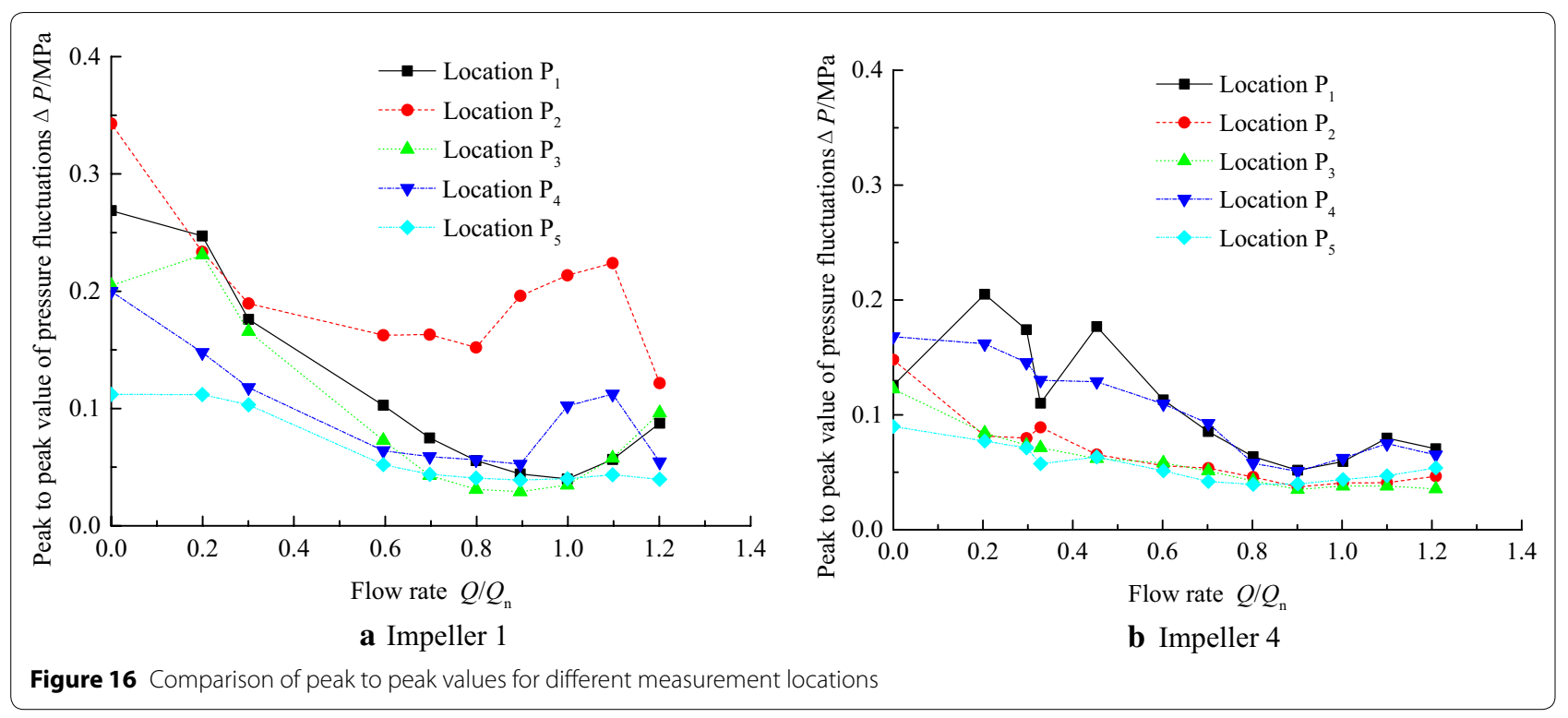

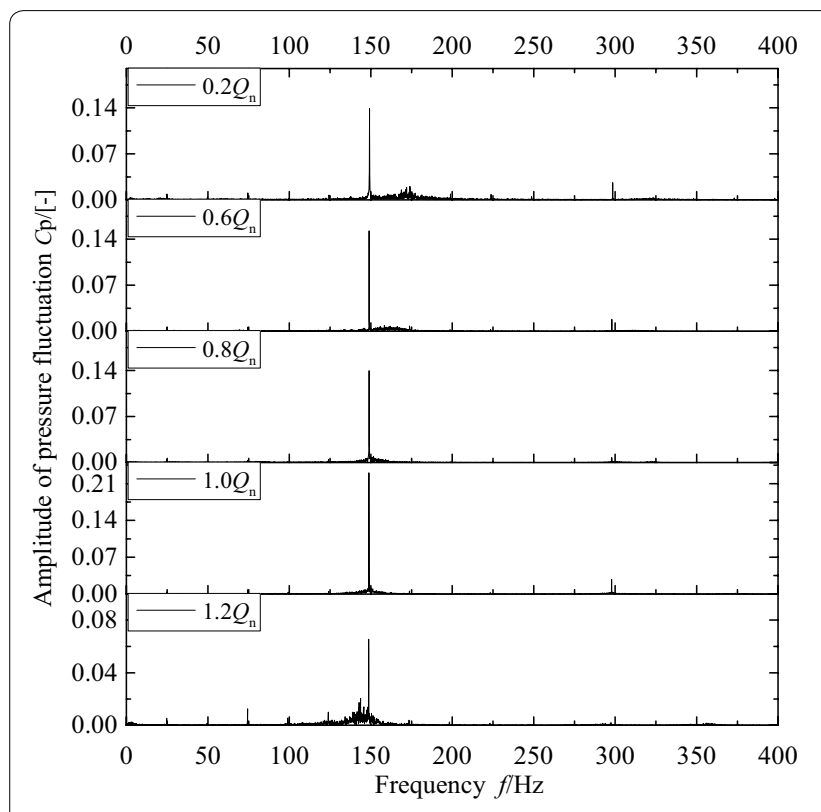

a Impeller 1, Measurement location $\mathrm{P}_{2}$

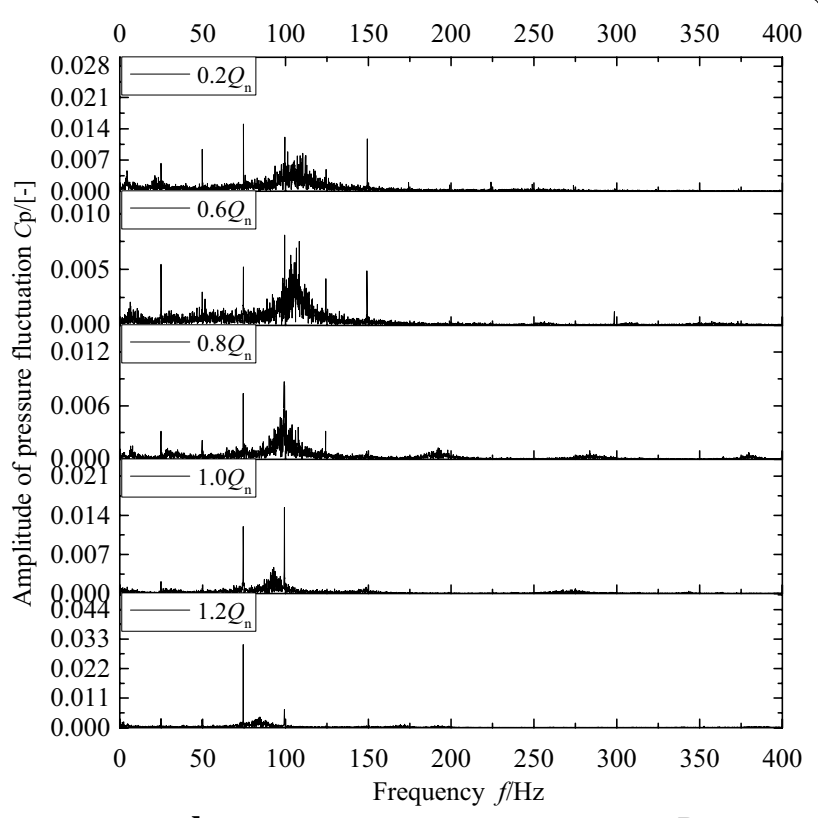

b Impeller 4, Measurement location $\mathrm{P}_{2}$

Figure 17 Frequency spectra of pressure fluctuations at location $\mathrm{P}_{2}$ for five flow rates

tenth of that in impeller 1 . The broadband of these two impellers demonstrates the same behaviors. The center frequency of the broadband component decreases with increasing flow rate. For impeller 4 , some low frequencies of the pressure fluctuations below $0.6 Q_{n}$ may be induced by the shedding of stall cells as investigated by Zhou [28].

The above results suggest that the stagger angle definitely affects the pressure fluctuation characteristics in the volute casing; in particular, it decreases the amplitude on the blade passage frequency. When the impeller stagger angle is $24^{\circ}$ or $36^{\circ}$, the distribution of pressure fluctuations in the volute casing becomes more uniform than the other impeller configurations, and the level of pressure fluctuation can be reduced by up to $50 \%$. Staggered impellers may redistribute the flow pattern at the region of the impeller outlet and affect the jet-wake flow field. 
In this way, the staggered impeller changes the strength of the interaction between the impeller and the volute tongue.

\section{Conclusions}

1. Five impeller configurations with the same test rig system are investigated. The pressure fluctuations are captured along the walls of the semi-casing suction chamber and the volute casing. The time domain and frequency spectra are carefully identified using statistical methods and Fast Fourier Transform.

2. The stagger angles exert negligible effects on the characteristics of head and efficiency. Compared with the traditional parallel impeller, the staggered impeller slightly decreases the pump head.

3. The distributions of pressure fluctuations are relatively uniform along the suction chamber wall, and the maximum pressure fluctuation amplitude is reached near the inlet tongue region.

4. The dominant pressure fluctuation frequencies are composed of impeller rotation frequency and its harmonic frequencies, and half blade passage frequency.

5. The stagger angle exerts minimal effects on the pressure fluctuations in the suction chamber but greatly affects the pressure fluctuation characteristics in the volute casing. In particular, this parameter decreases the amplitude on the blade passage frequency. When the impeller configuration is nearly halfway staggered, the distribution of pressure fluctuations in the volute casing becomes more uniform than the other impeller configurations, and the level of pressure fluctuation may be reduced by up to $50 \%$.

\section{Authors' contributions}

DCF carried out the experiments, participated in the data post processing and drafted the manuscript. FJW provided guidances on the experiment design and the data analysis methods. PJZ and RFX participated in the experiments. ZFY sponsored the research, participated in the entire process of the research. All authors read and approved the final manuscript.

\section{Author details \\ ${ }^{1}$ College of Water Resources and Civil Engineering, China Agricultural Uni- versity, Beijing 100083, China. ${ }^{2}$ Beijing Engineering Research Center of Safety and Energy Saving Technology for Water Supply Network System, China Agri- cultural University, Beijing 100083, China. ${ }^{3}$ College of Mechanical Engineering, Zhejiang University of Technology, Hangzhou 310014, China.}

\section{Authors' Information}

Da-Chun Fu, born in 1970, is currently a Ph.D. candidate at College of Water Resources and Civil Engineering, China Agricultural University, China. He received his master degree from China University of Petroleum (East China), China, in 2010. His research interests include operating stability and pressure fluctuation characteristics of centrifugal pumps. Tel: +86-137-01207037; E-mail: fudachun@hqcec.com.

Fu-Jun Wang, born in 1964, is currently a professor at China Agricultural University, China. He received his Ph.D. degree from Tsinghua University, China, in 2000. His research interests mainly include computational fluid dynamics of hydraulic machines, transient flow phenomena in pumping system, design theory of turbomachines and fluid-structure interaction. E-mail: wangfi@cau. edu.cn.
Pei-Jian Zhou, born in 1986, is currently a lecturer at Zhejiang University of Technology, China. He received his Ph.D. degree from China Agricultural University, China, in 2015. His research interests mainly include stall characteristics in centrifugal pumps. E-mail: Peijianzhou@gmail.com.

Ruo-Fu Xiao, born in 1976, is currently a professor at China Agricultural University, China. He received his Ph.D. degree from Huazhong University of Science and Technology, China, in 2004. His research interests mainly include flow theory of hydraulic machines, optimization design of turbomachines and fluids-structure interaction.E-mail: Xrf@cau.edu.cn.

Zhi-Feng Yao, born in 1984, is currently an associate professor at China Agricultural University, China. He received his Ph.D. degree from China Agricultural University, China, in 2013. His research interests mainly include hydrodynamic damping of hydraulic machines, pressure fluctuation characteristics of centrifugal pump, and design theory of pumping stations. Tel: +86-15811134516; E-mail: yzf@cau.edu.cn.

\section{Acknowledgements}

Supported by National Natural Science Foundation of China (Grant Nos. 51621061, 51139007, 51409247), and National Science and Technology Support Project of China (Grant No. 2015BAD20B01).

\section{Competing interests}

The authors declare that they have no competing interests.

\section{Ethics approval and consent to participate}

Not applicable.

\section{Publisher's Note}

Springer Nature remains neutral with regard to jurisdictional claims in published maps and institutional affiliations.

Received: 17 January 2017 Accepted: 14 January 2018

Published online: 28 February 2018

\section{References}

1. F J Wang. Pump and pumping station. 2nd ed. Beijing: China Agricultural Press, 2011

2. LY Qi, K Dai, R Jiang, et al. Analysis on rationality of speed-regulating operation of pumps in Huinanzhuang puming station. Water Resources and Hydropower Engineering, 2009, 40(7): 70-75. (in Chinese)

3. A Posa, A Lippolis, E Balaras. Investigation of separation phenomena in a radial pump at reduced flow rate by large-eddy simulation. Journal of Fluids Engineering, 2016, 138(12): 121101-1-13.

4. J F Gülich Centrifugal pumps.2nd ed. Berlin: Springer, 2010.

5. J González, J M F Oro, K M A Díaz, et al. Unsteady flow patterns for a double suction centrifugal pump. Journal of Fluids Engineering. 2009, 131(7): 071102-1-9.

6. S Guo, Y Maruta, H Okamoto, et al. Complex pressure fluctuations and vibrations in a pump-water tunnel system. Proceedings of the 4th ASME/ JSME Joint Fluids Engineering Conference, Hawaii, USA. July, 2003: 19-26.

7. F K Benra, H J Dohmen. Theoretical and experimental investigation on the flow induced vibrations of a centrifugal pump. Proceedings of the 5 th Biennial International Pipeline Conference by ASME, Calgary, Alta., Canada. 2004: 39-46.

8. B Rose. Detecting NPSH available \& cavitation in pumps through high frequency pressure measurement. Cranfield: Cranfield University, School of Engineering, 2007.

9. Y Liu, Sh Q Yuan, J P Yuan. Overview of pressure fluctuation in centrifugal pump. Fluid Machinery, 2008, 36(9): 33-37. (in Chinese)

10. Zh F Yao, F J Wang, LX Qu, et al. Experimental investigation of timefrequency characteristics of pressure fluctuations in a double-suction centrifugal pump. Journal of Fluids Engineering, 2011, 133(10): 1076-1081.

11. S Chu, R Dong, J Katz. Relationship between unsteady flow pressure fluctuations and noise in a centrifugal pump-Part A: Use of PDV data to compute the pressure field. Journal of Fluids Engineering, 1997, 117(1): 24-29. 
12. SChu, R Dong, J Katz. Relationship between unsteady flow, pressure fluctuations, and noise in a centrifugal pump-Part B: Effects of blade-tongue interactions. Journal of Fluids Engineering, 1997, 117(1): 30-35.

13. H Stel, G D L Amaral, C O R Negrão. Numerical analysis of the fluid flow in the first stage of a two-stage centrifugal pump with a vaned diffuser. Journal of Fluids Engineering, 2013, 135(7): 071104.

14. J Pei, W J Wang, Sh Q Yuan, et al. Optimization on the impeller of a lowspecific-speed centrifugal pump for hydraulic performance improvement. Chinese Journal of Mechanical Engineering, 2016, 29(5): 1-11.

15. ZX Gao, W R Zhu, L Li, et al. Numerical and experimental study of unsteady flow in a large centrifugal pump with stay vanes. Journal of Fluids Engineering, 2014, 136(7): 071101.

16. S S Yang, H L Liu, F Y Kong, et al. Effects of the radial gap between impeller tips and volute tongue influencing the performance and pressure fluctuations of pump as turbine. Journal of Fluids Engineering, 2014, 136(5): 054501

17. M Solis, F Bakir, S Khelladi, et al. Numerical study on pressure fluctuations reduction in centrifugal pumps: Influence of radial gap and inlet tongue blades. ISRN Mechanical Engineering, 2011 (2): 479594.

18. I Hayashi, S Kaneko. Pressure pulsations in piping system excited by a centrifugal turbomachinery taking the damping characteristics into consideration. Journal of Fluids and Structure, 2014, 45(1): 216-234.

19. A Alqutub, A Khalifa, Y Khulief. Experimental investigation of the effect of radial gap and impeller blade exit on flow-induced vibration at the blade passage frequency in a centrifugal pump. International Journal of Rotating Machinery, 2009(1023-621X): 1-9.

20. R Spence, J Amaral-Teixeira. A CFD parametric study of geometrical variations on the pressure pulsations and performance characteristics of a centrifugal pump. Computers \& Fluids, 2009, 38(6): 1243-1257.
21. M Yang, F J Wang, LX Qu, et al. Performance improvement of double-suction centrifugal pump by using CFD. 24th IAHR Symposium on Hydraulic Machinery and Systems, October 27-31, 2008, Fozdo Iguassu, Brazil.

22. H Li, Z Shen, L Ji, et al. Research on hydraulic structure of low pressure pulsations double-suction pumps based on unsteady flow numerical simulation. Proceeding of the ASME 2009 Fluids Engineering Division Summer Meeting, Vail Colorado, USA, 2009.

23. Z F Yao, F J Wang, M Yang, et al. Effects of impeller type on pressure fluctuations in double-suction centrifugal pump. Journal of Mechanical Engineering, 2011, 47(12): 133-137 + 143. (in Chinese)

24. L L Zheng, H S Dou, X P Chen, et al. Numerical simulation of pressure fluctuation around the tongue region in a Centrifugal pump. IOPConference Series: Earth and Environmental Science, Volume 49, Pumps, 2016, 49(3): 032012.

25. W Guo, F B Bu, G P Li. Coherence analysis study of pressure fluctuation and vibration signal in centrifugal pump. Ship Engineering, 2016 (9): 71-74. (in Chinese)

26. WY Zhao, LY Xue, J G Ge, et al. Influence of blade staggering disposition with different angles on pressure pulsation in volute of double-suction centrifugal pump. Journal of Lanzhou University of Technology, 2016, 01: 56-60. (in Chinese)

27. C C Song, Y S Su. Effect of modification to tongue and basic circle diameter on vibration in a double-suction centrifugal pump. Mechatroincs, 2015, 02: 76-80.

28. P J Zhou, F J Wang, Z F Yao. Investigation of pressure fluctuation in centrifugal pump impeller under rotating stall conditions. Transactions of the Chinese Society for Agricultural Machinery, 2015, 46(10): 56-61. (in Chinese)

\section{Submit your manuscript to a SpringerOpen ${ }^{\odot}$ journal and benefit from:}

- Convenient online submission

- Rigorous peer review

- Open access: articles freely available online

- High visibility within the field

- Retaining the copyright to your article

Submit your next manuscript at springeropen.com 